\title{
Functional characterization of the Mycobacterium tuberculosis serine/threonine kinase PknJ
}

\author{
Jichan Jang, ${ }^{1,2}$ Alexandre Stella, ${ }^{3,4}$ Frédéric Boudou, ${ }^{1}$ Florence Levillain, ${ }^{3,4}$ \\ Eliette Darthuy, ${ }^{3,4}$ Julien Vaubourgeix, ${ }^{3,4}$ Chongzhen Wang, ${ }^{3,4}$ \\ Fabienne Bardou, ${ }^{3,4}$ Germain Puzo, ${ }^{3,4}$ Martine Gilleron, ${ }^{3,4}$ \\ Odile Burlet-Schiltz, ${ }^{3,4}$ Bernard Monsarrat, ${ }^{3,4}$ Priscille Brodin, ${ }^{2}$ \\ Brigitte Gicquel $^{1}$ and Olivier Neyrolles ${ }^{1,3,4}$ \\ ${ }^{1}$ Unit of Mycobacterial Genetics, Institut Pasteur, Paris, France \\ ${ }^{2}$ Inserm Equipe Avenir Biology of Intracellular Pathogens, Institut Pasteur Korea, Seoul, Republic of \\ Korea \\ ${ }^{3}$ Centre National de la Recherche Scientifique, Institut de Pharmacologie et de Biologie Structurale, \\ F-31077 Toulouse, France \\ ${ }^{4}$ Université de Toulouse, Université Paul Sabatier, Institut de Pharmacologie et de Biologie \\ Structurale, F-31077 Toulouse, France
}

Correspondence

Olivier Neyrolles

olivier.neyrolles@ipbs.fr

Received 13 January 2010

Revised 15 February 2010

Accepted 18 February 2010

\begin{abstract}
Eukaryotic-like Ser/Thr protein kinases (STPKs) are present in many bacterial species, where they control various physiological and virulence processes by enabling microbial adaptation to specific environmental signals. PknJ is the only member of the 11 STPKs identified in Mycobacterium tuberculosis that still awaits characterization. Here we report that $\mathrm{PknJ}$ is a functional kinase that forms dimers in vitro, and contains a single transmembrane domain. Using a high-density peptide-chip-based technology, multiple potential mycobacterial targets were identified for PknJ. We confirmed PknJ-dependent phosphorylation of four of these targets: PknJ itself, which autophosphorylates at $\mathrm{Thr}^{168}, \mathrm{Thr}^{171}$ and $\mathrm{Thr}^{173}$ residues; the transcriptional regulator EmbR; the methyltransferase MmaA4/Hma involved in mycolic acid biosynthesis; and the dipeptidase PepE, whose encoding gene is located next to $p k n J$ in the mycobacterial genome. Our results provide a number of candidate phospho-targets for PknJ and possibly other mycobacterial STPKs that could be studied to investigate the role of STPKs in M. tuberculosis physiology and virulence.
\end{abstract}

\section{INTRODUCTION}

Protein phosphorylation in response to environmental changes is a common mechanism of adaptation in both eukaryotes and prokaryotes. In prokaryotes, the primary signal transduction mechanism relies on a two-component system consisting of a histidine kinase and a response regulator. The histidine kinase undergoes autophosphorylation in response to an environmental signal, and subsequently phosphorylates an aspartate residue in the response regulator, which binds to specific DNA sequences (Inouye \& Nariya, 2008). This two-component system is ubiquitous in prokaryotes and regulates a variety of processes, including nutrient acquisition, energy metabolism and virulence, while eukaryotes mostly use serine/ threonine and tyrosine phosphorylation systems to create highly sophisticated regulatory networks (Zhang et al.,

Abbreviation: STPK, Ser/Thr protein kinase.

Supplementary material is available with the online version of this paper.
1998). The first eukaryotic-like protein serine/threonine kinase (STPK) identified in a prokaryote was discovered in Myxococcus xanthus (Munoz-Dorado et al., 1991). Accumulating bacterial genome sequencing data has further shown that many prokaryotes use eukaryotic-like STPKs for translating external signals into cellular responses (Cozzone, 2005; Deutscher \& Saier, 2005). The completion of the Mycobacterium tuberculosis genome sequencing project showed that this pathogen contains 11 STPK-encoding genes, namely $p k n A, p k n B$ and $p k n D-L$ (Cole et al., 1998). All the corresponding enzymes except PknJ have been structurally and/or functionally characterized (Av-Gay et al., 1999; Canova et al., 2008; Chaba et al., 2002; Cowley et al., 2004; Dasgupta et al., 2006; Duran et al., 2005; Fernandez et al., 2006; Gay et al., 2006; Good et al., 2004; Gopalaswamy et al., 2004; Greenstein et al., 2007; Grundner et al., 2005; Kang et al., 2005; Koul et al., 2001; Kumar et al., 2009; Lakshminarayan et al., 2008; Mieczkowski et al., 2008; Molle et al., 2003a, b, 2004, 2006b; Ortiz-Lombardia et al., 2003; Parikh et al., 2009; 
Park et al., 2008; Perez et al., 2006; Sharma et al., 2006b; Thakur \& Chakraborti, 2006, 2008; Veyron-Churlet et al., 2009; Villarino et al., 2005; Young et al., 2003). They are involved in the control of various processes, including cell growth and morphology (Chaba et al., 2002; Dasgupta et al., 2006; Gopalaswamy et al., 2009; Kang et al., 2005, 2008), molecular transport (Molle et al., 2004), glucose uptake and metabolism (Deol et al., 2005), glutamate metabolism, at least in M. tuberculosis (Cowley et al., 2004; O'Hare et al., 2008) but possibly not in Mycobacterium bovis BCG (Nguyen et al., 2005), fatty acid synthesis (Molle et al., 2006a; Veyron-Churlet et al., 2009), transcription factor activity and gene transcription (Canova et al., 2008; Cohen-Gonsaud et al., 2009; Greenstein et al., 2007; Kumar et al., 2009; Park et al., 2008; Sharma et al., 2006b), and host-pathogen interactions (Walburger et al., 2004). The sensor domains of these molecules have been barely investigated to date, but it is thought that ligand recognition by the sensor domain induces activation through transmission of conformational changes to the intracellular kinase domain (Good et al., 2004). Some of these STPKs are essential for mycobacterial growth and thus constitute promising antibacterial targets (Fernandez et al., 2006; Szekely et al., 2008).

In contrast to all other M. tuberculosis STPKs, PknJ has no detectable orthologue in mycobacterial species outside the M. tuberculosis complex (Narayan et al., 2007), and we recently proposed that the $\mathrm{PknJ}$-encoding gene arose in the M. tuberculosis ancestor though horizontal gene exchange with environmental species (Becq et al., 2007). This suggests that $\mathrm{PknJ}$ may be involved in unique aspects of M. tuberculosis physiology. Here we used a combination of heterologous expression, high-density peptide-chip analysis and mass spectrometry to show that PknJ has a functional kinase domain that can phosphorylate a number of substrates.

\section{METHODS}

Strains and growth conditions. The bacterial strains used in this study are listed in Supplementary Table S1, available with the online version of this paper. M. tuberculosis CDC 1551 and M. tuberculosis CDC 1551 pknJ::Tn and pepE::Tn mutants were obtained from Colorado State University (Lamichhane et al., 2003), and were grown in Middlebrook 7H9 supplemented with $10 \%$ oleic acid-albumindextrose-catalase (OADC; Difco) and $0.05 \%$ Tween 80. When required (for the mutant strains), kanamycin $\left(20 \mu \mathrm{g} \mathrm{ml}{ }^{-1}\right.$ ) was added to the mycobacterial cultures. The $p k n J / \operatorname{Rv} 2088$ mutant carries a transposon insertion at nt 60 ; the $p e p E / R v 2089 \mathrm{c}$ mutant carries a transposon insertion at nt 704 .

Protein topology analysis. Membrane topology predictions for PknJ were examined using тмнмм Server version 2.0 (http://www. cbs.dtu.dk/services/TMHMM/). We constructed a series of translational fusions of the $p k n J$ gene fragments to both the phoA gene expressing a truncated alkaline phosphatase (PhoA) and the $g f p$ gene expressing green fluorescent protein (GFP). PCR with a forward primer for the $5^{\prime}$ end of the $p k n J$ gene paired with three different reverse primers (Table S2) was used to amplify appropriate sequences using chromosomal DNA from M. tuberculosis strain H37Rv as a template. The PCR amplicons were inserted into pUC19-phoA (pPhoA) and pJFX2, and the resulting plasmids containing different truncated $p k n J:: p h o A$ and $p k n J:: g f p$ fusions were used to transform Escherichia coli strains CC118 (a strain with the phoA gene deleted) and XL1-Blue, respectively. The plasmids used in this study are described in Table S1. The alkaline phosphatase assay was performed as described by LeBlanc \& Beatty (1996). GFP expression was observed under a fluorescence microscope (Leica).

\section{Purification of recombinant PknJ, PepE, EmbR and MmaA4/}

Hma. An 843 bp pknJ fragment was amplified from M. tuberculosis H37Rv genomic DNA using primers PknJFd and PknJRv (Table S2). The amplified PCR fragment was inserted between the NdeI and HindIII sites of pET-28b $(+)$ (Novagen). E. coli BL21 Sta (DE3) cells (Invitrogen) were transformed with the resulting plasmids and the purified recombinant protein was used for the PepChip array kinase assay only. In parallel, an 807 bp PCR product of $p k n J$ amplified with primers pMAL $p k n J \mathrm{Fd}$ and pMALpknJRv (Table S2) was ligated into vector pMAL-c2X (New England Biolabs) for overproduction of its gene product. The resulting ligation product, pMAL-c2X-pknJ, was transformed into E. coli BL21 Star (DE3) (Invitrogen) and the resulting recombinant protein was used for all assays described in this paper, except the PepChip assay. The DNA fragments encoding recombinant PepE and EmbR were generated using various primers containing the additional 4 bp sequence $5^{\prime}$-CACC- 3 ' necessary for directional cloning on the $5^{\prime}$ end (Table S2). The amplicons generated were ligated into vector pET100/D-TOPO (Invitrogen). The BL21 Star (DE3) cells were transformed with the plasmids and incubated overnight at $37{ }^{\circ} \mathrm{C}$ with shaking in LB medium. The resulting culture was added to $500 \mathrm{ml}$ of the same medium and grown at $37^{\circ} \mathrm{C}$ to $\mathrm{OD}_{600} \sim 0.4$. Enzyme overproduction was induced by adding IPTG (1 mM final concentration, Sigma) and shaking (120 r.p.m.) at $16{ }^{\circ} \mathrm{C}$ for $30 \mathrm{~h}$. For protein purification, cells were harvested by centrifugation and lysed by sonication in a buffer containing $20 \mathrm{mM}$ Tris/HCl (pH 7.4), $200 \mathrm{mM} \mathrm{NaCl}$ and protease inhibitor cocktail (Roche). Recombinant protein was purified using HisTrap HP columns (GE Healthcare) and affinity columns (amylose resin, New England Biolabs) according to the manufacturer's instructions. This purified protein was used for in vitro kinase assays. Recombinant MmaA4/Hma was produced as previously described (Boissier et al., 2006).

In vitro kinase assay. Kinase assays were conducted in $20 \mu \mathrm{l}$ kinase buffer (25 mM Tris/HCl, $5 \mathrm{mM} \mathrm{MgCl} 2,2 \mathrm{mM} \mathrm{MnCl}_{2}, \mathrm{pH}$ 7.4). All reactions were started by adding ATP $(100 \mu \mathrm{M})$ and recombinant PknJ $(4.5 \mu \mathrm{g})$. The reaction mixture was incubated with $15 \mu \mathrm{g}$ recombinant substrate protein at $32{ }^{\circ} \mathrm{C}$ for $25 \mathrm{~min}$ and terminated by addition of Laemmli SDS sample buffer. For protein migration under non-denaturing conditions, DTT was omitted from the loading buffer. The proteins were resolved by SDS-PAGE and phosphorylations were revealed by Pro-Q Diamond Phosphoprotein Gel staining (Invitrogen) according to the manufacturer's instructions (Martin et al., 2003; Sun et al., 2008). The phosphorylation was visualized by Typhoon 9400 PhosphorImager (Molecular Dynamics). In some experiments, proteins were separated by SDS-PAGE, electrotransferred to nitrocellulose membrane and Western blotting detection was performed using a mouse anti-phosphothreonine antibody (Invitrogen).

LC-MS/MS analysis. Appropriate bands were cut out of gels, and excised gel slices were digested with endoprotease Glu-C (Sequencing Grade from Staphylococcus aureus V8, Sigma) followed by trypsin (Sequencing Grade Modified Trypsin, V511A, Promega). The tryptic digests were analysed by online LC-MS/MS on an LTQ-FT Orbitrap hybrid mass spectrometer (Thermo Electron). The samples were run on a $75 \mu \mathrm{m}$ i.d. $\times 15 \mathrm{~cm}$ PepMap C18 column after loading onto a $300 \mu \mathrm{m}$ i.d. $\times 5 \mathrm{~mm}$ PepMap C18 precolumn (Dionex). The flow rate 


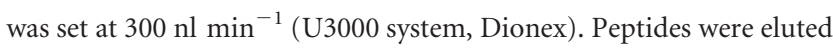
using a $5-50 \%$ linear gradient of solvent B in 50 min (solvent A was $0.2 \%$ formic acid in $5 \%$ acetonitrile and solvent B was $0.2 \%$ formic acid in $90 \%$ acetonitrile). The LTQ-FT Orbitrap mass spectrometer was operated in the data-dependent mode. In brief, a scan cycle was initiated with a full scan of high mass accuracy $(\mathrm{m} / \mathrm{z} 300-2000)$ in the Orbitrap, which was followed by five MS/MS scans in the linear ion trap on the five most abundant precursor ions, with dynamic exclusion of previously selected ions. Singly charged ions were excluded from the MS/MS analysis.

MS/MS data analysis. The MASCOT search engine was used for protein identification by searching against $M$. tuberculosis complex in the Sprot-Trembl_20080901 database (24 526 sequences). Specificity of Glu-C and trypsin digestion was set for cleavage after D, E, K or R, and two missed cleavage sites were allowed. Carbamidomethylation of cysteines, oxidation of methionines and phosphorylation of serine and threonine were set as variable modifications. All MS/MS spectra of modified peptides of interest were manually validated.

Site-directed mutagenesis. Mutants of $p k n J$ were generated by using a Phusion site-directed mutagenesis kit (Finnzymes). The pMAL-c2X-pknJ template ( $10 \mathrm{pg})$, sense and antisense primers $(0.5$ $\mu \mathrm{M})$ were added to PCR tubes containing $0.2 \mathrm{mM}$ dNTPs, $0.01 \mathrm{U}$ Phusion DNA polymerase and $1 \times$ reaction buffer at final concentration. The programme used for the PCR consisted of $30 \mathrm{~s}$ of initial denaturation at $98{ }^{\circ} \mathrm{C}$, followed by 25 cycles of $98{ }^{\circ} \mathrm{C}, 55{ }^{\circ} \mathrm{C}$ and $68{ }^{\circ} \mathrm{C}$, each for $20 \mathrm{~s}$. The final extension step of the PCR was $72{ }^{\circ} \mathrm{C}$ for $10 \mathrm{~min}$. All fragments were separated on a $1 \%(\mathrm{w} / \mathrm{v})$ agarose gel, purified with a QIAquick Gel Extraction kit (Qiagen) and were used to transform XL1-Blue competent cells. The resultant mutations were confirmed by sequencing.

PepChip array kinase assay. The PepChip Microarray kinase assay was conducted by LC Sciences (Houston, TX, USA). The full slide contained 582 sequences matching the $\mathrm{xx}(\mathrm{LVI}) \mathrm{TxTxx}$ consensus sequence detected in the M. tuberculosis deduced proteome, with two redundancies. Each sequence is 8 -mer or longer and each substrate has its own corresponding negative control (i.e. substitute $\mathrm{S}, \mathrm{T}$ or $\mathrm{Y}$ with A). Multiple quality-control probes were included in each chip. For kinase assay, the peptide chip was incubated with blocking buffer $(1 \times$ TBS, $1 \%$ BSA, $0.05 \%$ Tween 20 , pH 6.8$)$ at $4{ }^{\circ} \mathrm{C}$ overnight with circulation. After incubation, the chip was washed with $1 \mathrm{ml}$ deionized water. For the kinase reaction, kinase reaction buffer containing purified recombinant $\mathrm{PknJ}\left(10 \mu \mathrm{g} \mathrm{ml}^{-1}\right)$ was added to the PepChip slide and incubated for $16 \mathrm{~h}$ at $25{ }^{\circ} \mathrm{C}$. The kinase reaction buffer contains $1 \times$ TBS, $5 \mathrm{mM} \mathrm{MgCl}, 2 \mathrm{mM} \mathrm{MnCl} 2,0.1 \mathrm{mM}$ ATP, $\mathrm{pH}$ 7.5. After incubation, the slide was washed twice with washing buffer $(1 \times$ TBS pH 7.5 and $1 \times$ TBS pH 6.8, respectively). For the detection of phosphorylated peptides, the peptide chip was stained with fivefold-diluted Pro-Q Diamond Phosphoprotein Gel Stain at $25{ }^{\circ} \mathrm{C}$ for $20 \mathrm{~min}$ according to manufacturer's instructions. Finally, the phosphorylated peptides were scanned and the result was quantified and analysed. Net signals for kinase substrate sequences (except internal controls) were determined by subtracting detectable signals for negative sequences from those for the corresponding kinase substrate sequences. These values are given in Supplementary Table S3. The ratios of the net signals and corresponding kinase substrate signals are presented as 'Net Signal Percentiles'. These percentiles are approximate measures of the contribution of the kinase to the signal of a kinase substrate sequence as percentages. Only sequences meeting at least the following conditions were listed as detectable: signal intensity higher than $3 \times$ (background standard deviation); spot $\mathrm{CV}<0.5$. CV is calculated as (standard deviation)/ (signal intensity) and the signals from at least $50 \%$ of the repeat probes were above the detection threshold. Background was defined as $10 \%$ of the lowest signals from the 3968 spots; background standard deviation was defined as the standard deviation of the $10 \%$ of the lowest signals (about 397 spots). Only signals higher than $3 \times$ (background standard deviation) were listed as detectable in the 'simple detectable' sheet. Spot CV was defined as the CV within a spot after its intensity and standard deviation were extracted from an image by ArrayPro software. It measures spot uniformity. Only spots with spot $\mathrm{CV}<0.5$ were used for calculation of detectable signals. There were usually three replicates on an array. If the signals were from at least $50 \%$ of the repeat probes, then it meant that 2 out of the 3 repeats, or 3 out of the 3 repeats, showing signals were considered as positives, and 1 out of 3 repeats showing signals were not considered as positive.

Macrophage and mouse infection. Bone-marrow-derived macrophages from female $\mathrm{BALB} / \mathrm{c}$ mice were isolated and infected as described previously (Rousseau et al., 2004). For activation, macrophages were pre-stimulated with IFN- $\gamma$ at a concentration of $1000 \mathrm{U}$ $\mu \mathrm{l}^{-1}$ for $4 \mathrm{~h}$ prior to infection. The cells were infected for $4 \mathrm{~h}$, then washed six times with pre-warmed culture medium, lysed at various times thereafter and plated onto 7H11-agar medium containing $10 \%$ OADC for c.f.u. scoring. For the virulence and survival analysis, 6- to 8 -week-old female BALB/c mice were infected intranasally with $10^{3}$ c.f.u. of M. tuberculosis strain CDC 1551 or its pknJ transposon mutant. At each time point, mice were killed, and the spleen and lungs were harvested and homogenized. Tenfold serial dilutions of organ homogenates were plated onto complete $7 \mathrm{H} 11$ medium and c.f.u. counted.

Lipid analysis and cytokine secretion assay. Details of these methods are given in the supplementary material.

\section{RESULTS}

\section{pknJ encodes a functional kinase}

Genomic organization of the $p k n J$ region is shown in Fig. 1(a). We inserted the kinase-domain-encoding genomic fragment of the $p k n J$ gene (bp 1-807) into an appropriate expression vector. The recombinant product was soluble and its purity was confirmed by gel migration and staining (not shown). We tested this construct for expression of a functional kinase using recombinant myelin basic protein $(\mathrm{MBP})$ as a substrate. Gel staining with Pro-Q Diamond (Martin et al., 2003; Sun et al., 2008) showed MBP phosphorylation in a time-dependent manner (Fig. 1b). This result was confirmed by Western blotting using an anti-phosphothreonine antibody (Fig. 1c). Autophosphorylation of PknJ was also observed (Fig. 1d) unless ATP was omitted from the reaction mixture. We did not detect a Pro-Q signal in the absence of ATP in the reaction mixture (Fig. 1d). This excludes the possibility of false-positive results.

\section{PknJ autophosphorylates at $\mathrm{Thr}^{168}, \mathrm{Thr}^{171}$ and Thr $^{173}$}

Mass spectrometry analysis of $\mathrm{PknJ}$ proteolytic digest revealed one phosphorylation site at threonine residue 168 and two phosphorylation sites at residues 171-173 (Fig. 2a). STPKs can phosphorylate both threonine and serine residues, so we investigated which two residues in the 
(a)

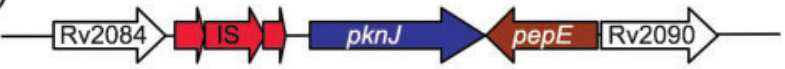

(b)

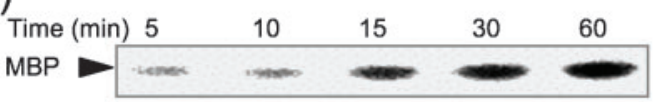

(c)

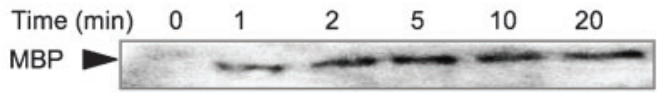

(d)

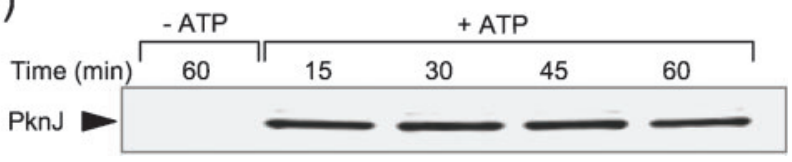

Fig. 1. M. tuberculosis PknJ contains a functional kinase domain. (a) Genomic organization of the pknJ/Rv2088 region in the M. tuberculosis chromosome according to Tuberculist nomenclature. IS, insertion sequences. (b, c) Phosphorylation assay using recombinant $M$. tuberculosis $\mathrm{PknJ}$ kinase domain produced in E. coli, and myelin basic protein (MBP) as a substrate. (d) Autophosphorylation assay of recombinant PknJ kinase domain in the presence or absence of ATP. Phosphoproteins in (b) and (d) were detected using Pro-Q Diamond; in (c), phosphoproteins were detected by Western blotting using an anti-phosphothreonine antibody.

$\mathrm{T}^{171} \mathrm{ST}^{173}$ tripeptide were in fact phosphorylated. A triple PknJ mutant where $\mathrm{Thr}^{168}$, $\mathrm{Thr}^{171}$ and $\mathrm{Thr}^{173}$ were replaced by Ala residues showed no sign of phosphorylation, confirming the specificity of Pro-Q staining for phosphoprotein in our experiment (Fig. 2b). We conclude that in vitro $\mathrm{PknJ}$ autophosphorylates at threonine residues 168, 171 and 173 only; in particular our results exclude the possibility that $\operatorname{Ser}^{172}$ is a phosphorylated residue. However, they do not rule out the possibility that there may be diverse PknJ isoforms containing variable numbers of phosphothreonine residues in the analysed samples.

\section{PknJ forms dimers and has a single transmembrane domain}

STPKs can form dimers, which probably contributes to signal transduction (Gay et al., 2006), and we assessed whether this was also true for PknJ. Analysis of the recombinant protein under non-denaturing conditions revealed two bands with apparent masses of 38 and $76 \mathrm{kDa}$, suggesting that the protein can form dimers in vitro (Fig. 3a). Most M. tuberculosis STPKs have a predicted transmembrane fragment (Av-Gay \& Everett, 2000; Narayan et al., 2007; Wehenkel et al., 2008) but the topology has been rigorously analysed for only a few of them. In silico analysis of PknJ revealed two potential transmembrane domains, which is unusual for mycobacterial STPKs (Fig. 3b). In order to study the topology of the protein, we constructed PhoA and GFP fusions with PknJ fragments of different lengths (Fig. 3c). PhoA is active only when expressed extracellularly (Manoil \& Beckwith, 1986), whereas GFP emits fluorescence only when located in the host cell cytoplasm (Feilmeier et al., 2000). The PhoA/GFP topology analysis has been successfully used to analyse protein topology in E. coli (Drew et al., 2002). Fluorescence (Fig. 3d) and phosphatase activity analysis (Fig. 3e) revealed that PknJ contains only one transmembrane fragment, most probably from residue 344 to residue 363 .

\section{PknJ phosphorylates EmbR, PepE and MmaA4/ Hma in vitro, and may have additional substrates}

The autophosphorylation residues of several M. tuberculosis STPKs, namely $\mathrm{PknB}, \mathrm{PknD}-\mathrm{F}$ and $\mathrm{PknL}$, have been identified (Duran et al., 2005; Lakshminarayan et al., 2008; Molle et al., 2003a, 2004; Perez et al., 2006). We used these results together with our results showing that PknJ $\mathrm{Thr}^{168}$, Thr ${ }^{171}$ and $\mathrm{Thr}^{173}$ are phosphorylated (Fig. 2), to generate a consensus sequence of phosphorylation sites. We searched the M. tuberculosis genome for the consensus sequence $x x($ LVI)TxTxx (Fig. 4a), and thereby identified 582 potential phosphorylation targets. These peptides were synthesized and included in a high-density peptide chip. The EmbR-derived peptide PLWTQLITAYY was also included in the chip because EmbR has been reported to be phosphorylated by several STPKs, including PknH (Molle et al., 2003b; Sharma et al., 2006a). Peptides in which all possible phosphorylation residues (Thr, Ser) in each target were replaced by Ala were included in the chip as negative controls. The chip was incubated with recombinant $\mathrm{PknJ}$ and phosphorylation was revealed by Pro-Q staining (Fig. 4b). A number of peptides were phosphorylated by incubation with PknJ, although the corresponding Ala control peptides remained unphosphorylated. The peptides giving a net signal percentile of $100 \%$ (see Methods) and the corresponding mycobacterial proteins according to Tuberculist nomenclature are given in Table 1. The EmbR-derived peptide gave a particularly strong signal (Fig. 4b, Table 1). Phosphorylation assays confirmed that PknJ can phosphorylate recombinant EmbR in vitro (Fig. 4c). Another peptide (kDvTRTYS) similar to the putative dipeptidase PepE and the methyltransferase MmaA4/Hma involved in mycolic acid biosynthesis was also identified, although with a net signal percentile below $100 \%$ (Fig. 4b, Table S3). The PepEencoding gene maps next to $\mathrm{pknJ}$ in the $M$. tuberculosis genome (Fig. 1a); many genes encoding the substrate(s) for several mycobacterial STPKs map in the vicinity of the gene encoding the cognate kinase itself (Narayan et al., 2007). Phosphorylation assays showed that recombinant PepE is a substrate for PknJ (Fig. 4d). Several mycobacterial STPKs have been shown to phosphorylate various enzymes involved in mycolic acid synthesis (Molle et al., 2006a; 
(a)

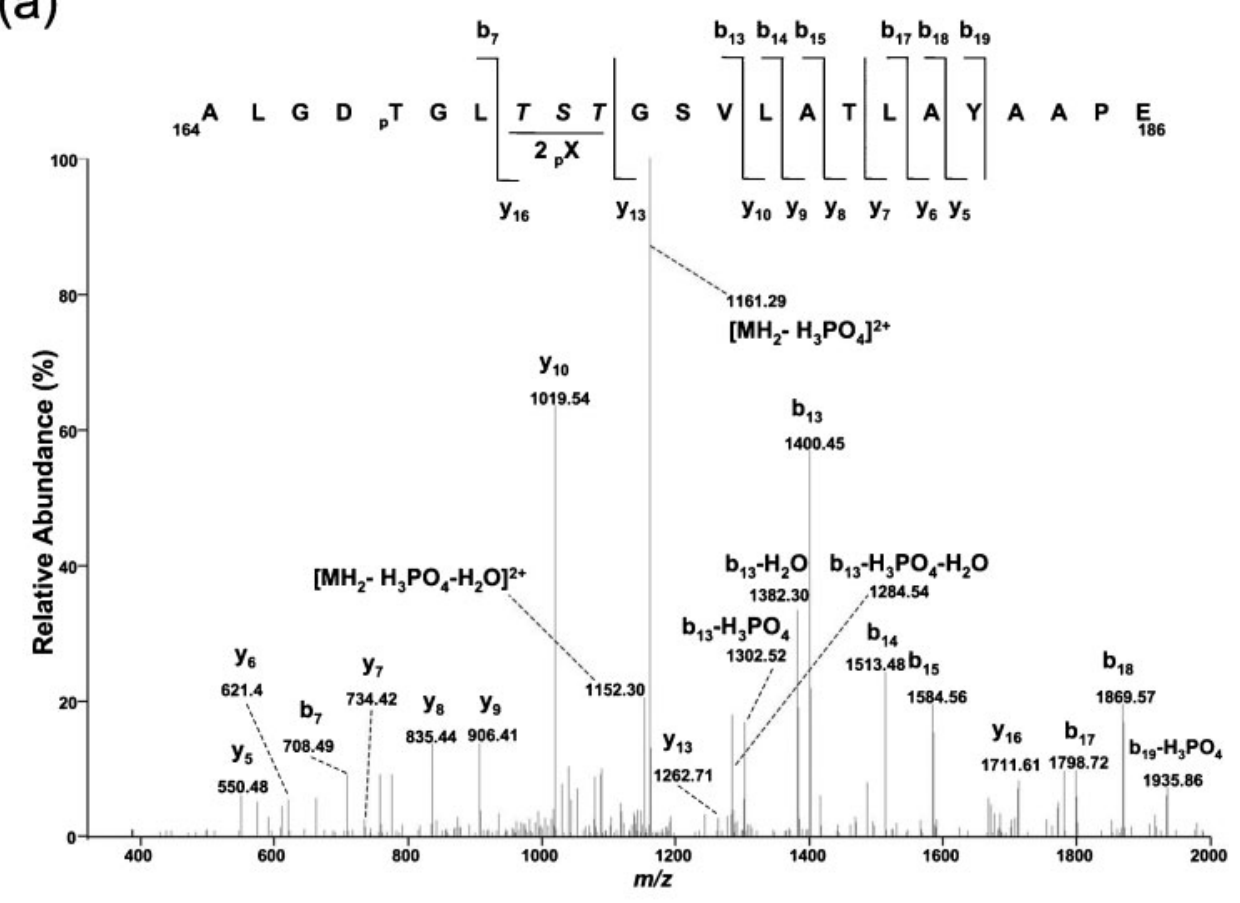

(b)

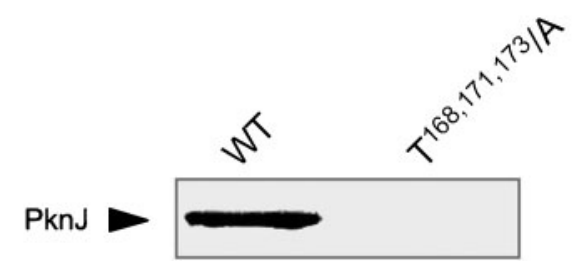

Fig. 2. The $M$. tuberculosis $\mathrm{PknJ}$ kinase domain autophosphorylates on $\mathrm{Thr}^{168}, \mathrm{Thr}^{171}$ and $\mathrm{Thr}^{173}$. (a) The MS/MS spectrum shows a specific triphosphorylated peptide sequence in PknJ, which is displayed above the spectrum. The ESI-MS/MS spectrum of the peptide with $\mathrm{m} / \mathrm{z} 1210.01$ (doubly charged ion) indicates that the peptide sequence ${ }_{164}$ ALGD $_{\mathrm{P}}$ TGLTSTGSVLATLAYAAPE $_{186}$ is phosphorylated at $\mathrm{Thr}^{168}$ and contains two other phosphorylation sites in the underlined amino acid sequence TST. The phosphorylation status of threonine (T) and serine (S) residues is indicated positively by the letter $p$ in the annotated spectrum. (b) Phosphorylation analysis of a PknJ kinase domain mutant form in which Thr ${ }^{168}$, $\mathrm{Thr}^{171}$ and $\mathrm{Thr}^{173}$ are each replaced by an Ala residue. Phosphoproteins were detected using Pro-O Diamond staining.

Veyron-Churlet et al., 2009), and we show here that recombinant Hma can be efficiently phosphorylated by PknJ, at least in vitro (Fig. 4e). These results show that PknJ has at least four substrates in vitro, namely EmbR, PepE, MmaA4/Hma and PknJ itself. The numerous peptide substrates identified in our peptide-chip screening assay suggest additional potential targets for PknJ.

\section{PknJ does not contribute to mycobacterial virulence in the mouse model}

A role for some M. tuberculosis STPKs in mycobacterial virulence in vitro and in vivo has been suggested (Gopalaswamy et al., 2009; Papavinasasundaram et al.,
2005; Walburger et al., 2004). We checked pknJ expression by RT-PCR. A pknJ transcript was indeed detected, at least in axenic culture conditions (data not shown). $M$. tuberculosis transposon mutants in $p k n J$ and $p e p E$ were generated elsewhere (Lamichhane et al., 2003). Interestingly, both the $p k n J$ - and the pepE-deficient strains showed a growth defect in minimal Sauton's broth, unless BSA was added to the medium (Fig. S1). To assess whether PknJ plays a part in host-cell infection, we infected bone-marrow-derived macrophages with the pknJ::Tn mutant or with the corresponding wild-type strain CDC1551. No difference in intracellular growth of the bacilli was observed (Fig. 5a). Infection of immunocompetent mice again revealed no particular phenotype for the $p k n J$ mutant 
(a)

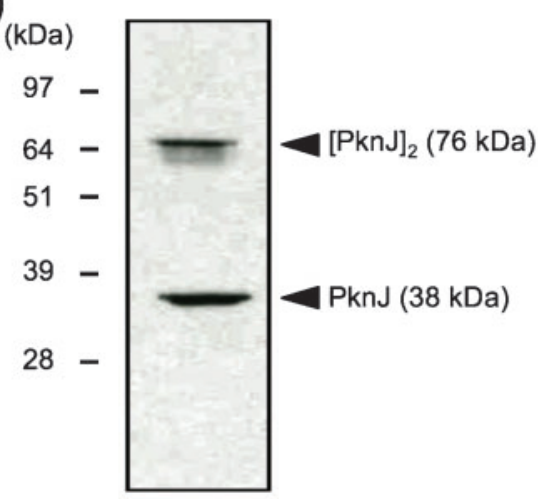

(b)

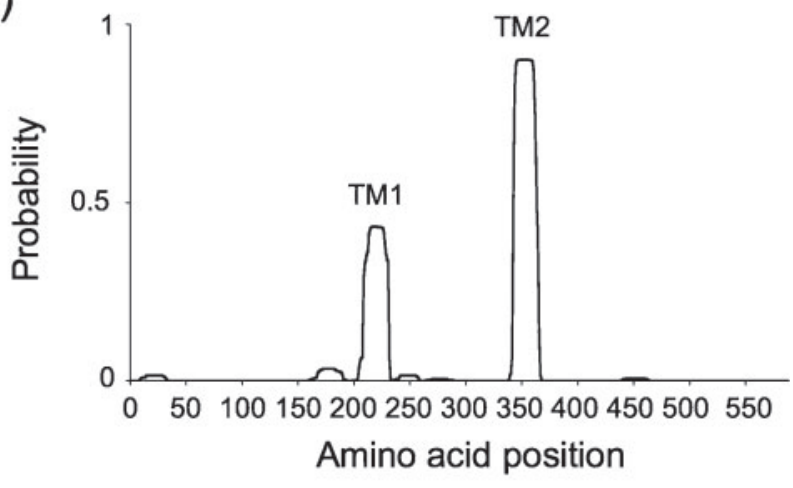

(c)

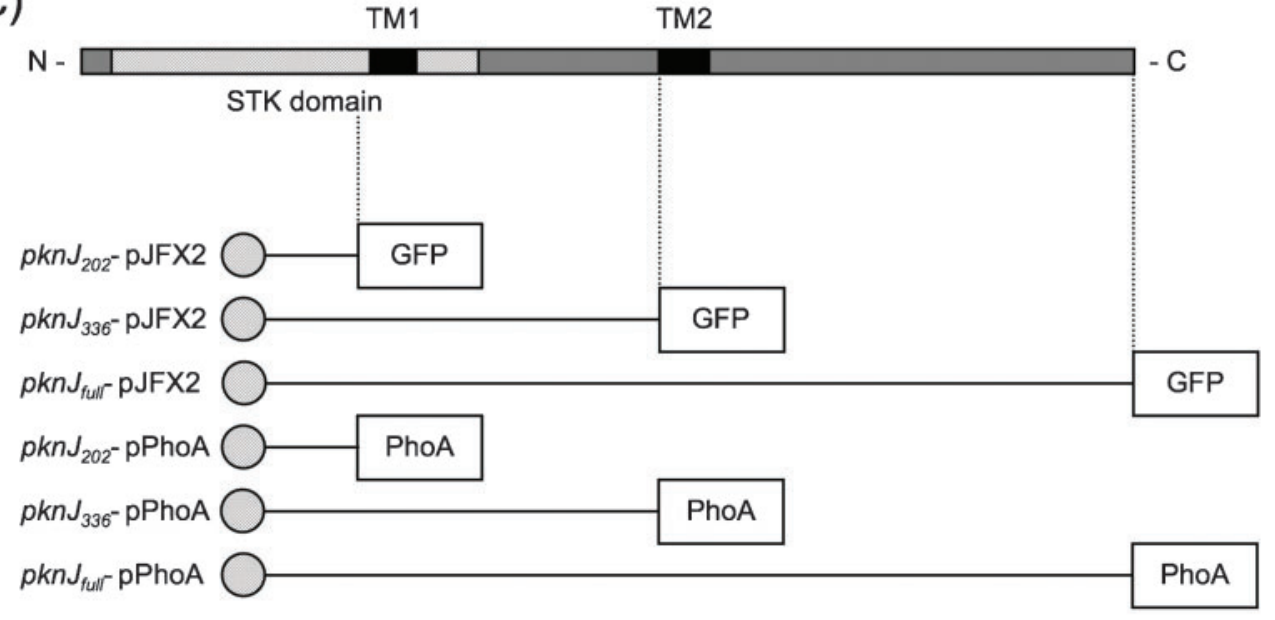

(d)

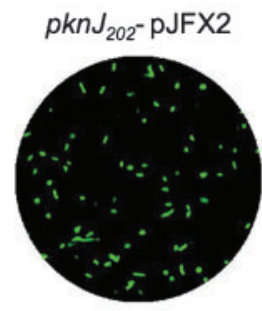

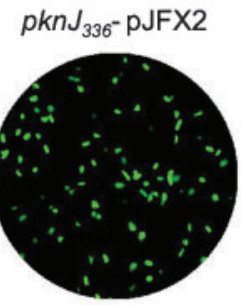

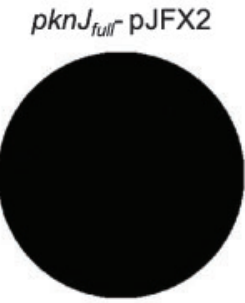

(e)

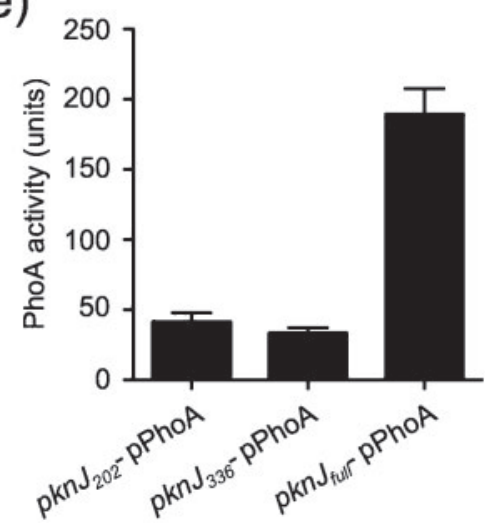

Fig. 3. The M. tuberculosis PknJ kinase domain forms dimers and PknJ has a single transmembrane fragment. (a) Electrophoretic mobility assay of recombinant $\mathrm{PknJ}$ kinase domain under non-denaturing conditions. Monomers (38 kDa) and dimers (76 kDa) are detected. (b) PknJ topology prediction (posterior probability of inside/outside/TM helix) using the TMHMM program (http://www.cbs. dtu.dk/services/TMHMM/). TM, transmembrane domain. (c) Gene fusion constructs used in topological analysis of PknJ. DNA fragments encoding PknJ regions were fused to GFP or to PhoA as indicated, and expressed in E. coli. (d) Fluorescence analysis of GFP fusions shown in (c). (e) Phosphatase activity of PhoA fusions shown in (c).

(Fig. 5b). The pknJ-deficient mutant was slightly hypervirulent in immunodeficient SCID mice (Fig. 5c), although we could not restore the phenotype of the wild-type strain in the complemented mutant strain. Mycobacterial lipids, such as phthiocerol dimycocerosates (DIMs) play a major part in M. tuberculosis virulence (Camacho et al., 1999; Cox 
(a)

PknJ

DFGIARALGDT--GLTSTGSVLATLAYAAPE

PknD

DFGIARAASDP--GLTQTGTAVGTYNYMAPE

PknF DFGIAGWVDDP $\underline{\text { S-GLTATNMTVGTVSYAAPE }}$

PknL

DFGLVRAVAAA--SITSTGVILGTAAYLSPE

PknB

DFGIARAIAD SNSVTQTAAVIGTAQYLSPE

PknE

DFGIASATTDE--KLTQLGNTVGTLYYMAPE

Consensus motif

$\underline{\mathbf{x x}}(\mathrm{LVI}) \mathrm{T} \underline{\mathrm{x}} \mathrm{T} \underline{\mathbf{x x}}$

(b)

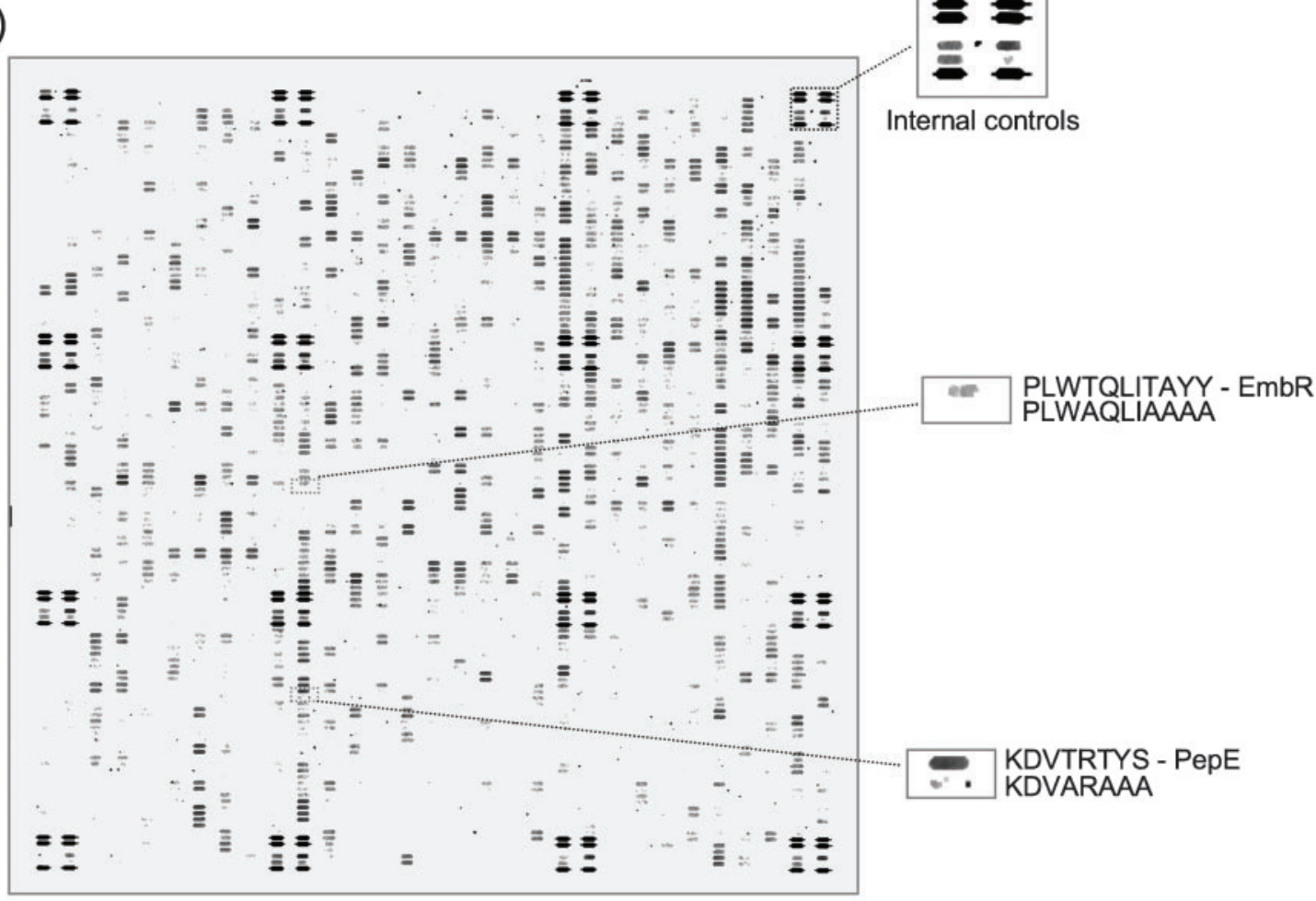

(c)

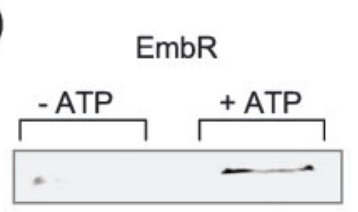

(d)

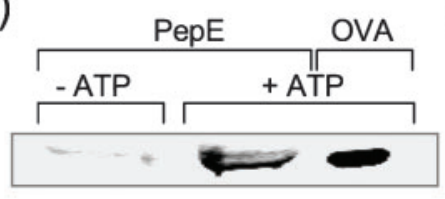

(e)

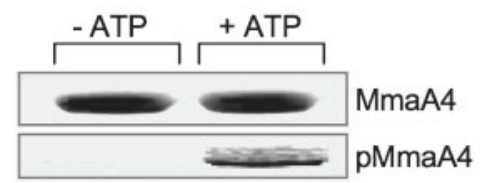

Fig. 4. The M. tuberculosis PknJ kinase domain phosphorylates multiple substrates. (a) A consensus phosphorylation sequence was deduced from known sequences in PknB, PknD-F, PknL and PknJ. (b) Phospho-chip analysis of peptide phosphorylation by recombinant PknJ kinase domain. Internal controls (phosphorylated and non-phosphorylated peptides), and the peptide substrates identified in EmbR (full match) and PepE (partial match), are shown. (c-e) Confirmation assays using recombinant M. tuberculosis EmbR (c), PepE (d) and MmaA4 (e) produced in E. coli as PknJ substrates in the presence or absence of ATP. Ovalbumin (OVA) is shown as a control. Phosphoproteins were revealed by Pro-Q Diamond staining.

et al., 1999), and our results showing that the polyketide synthases PpsA and PpsB, involved in DIM synthesis, are potential substrates for PknJ (Table 1) suggested that DIM synthesis may be under the control of PknJ-mediated phosphorylation. Extensive analysis of the lipid content of M. tuberculosis CDC1551 and its pknJ:: Tn mutant revealed no difference as regards DIM (Fig. S2a), other lipids, such as trehalose derivatives (TMM, TDM or DAT) (Fig. S2b) or phospholipids (PI, PE, CL, $\mathrm{PIM}_{2}, \mathrm{PIM}_{6}$ ) (Fig. S2c). Protein macroarray analysis of the host cell response to the mutant and the wild-type strains showed no difference in cytokine and chemokine synthesis (Fig. S3). 
Table 1. List of peptides, and corresponding M. tuberculosis genes and derived whole protein sequences, found to be phosphorylated by PknJ with no signal detected for the cognate $(\mathrm{T} / \mathrm{S} \rightarrow \mathrm{A})$ control

\begin{tabular}{|c|c|c|c|c|c|}
\hline No. $\dagger$ & Probe ID $\dagger$ & Sequence & Signal $\ddagger$ & Gene $\$$ & Function $\S$ \\
\hline 801 & PknJ_0401 & TPVTATRH & 172.8 & Rv3073c & \\
\hline 211 & PknJ_0106 & PDITATPA & 173.5 & $p g i$ & Glucose-6-phosphate isomerase \\
\hline $645^{\star}$ & PknJ_0323 & AWLTATPV & 173.6 & Rv1318c/Rv1320c & Adenylate cyclase \\
\hline 963 & PknJ_0482 & AVETNTFG & 173.9 & metH & Methionine synthesis \\
\hline 477 & PknJ_0239 & MQLTLTEL & 174.9 & $p p s B$ & PDIM synthesis \\
\hline 311 & PknJ_0156 & TSVTLTMS & 176.9 & $\operatorname{lp} r A$ & Lipoprotein \\
\hline 839 & PknJ_0420 & VQVTSTGV & 177.0 & Rv0479c & \\
\hline 571 & PknJ_0286 & DTVTGTAS & 177.2 & tal & Transaldolase \\
\hline 1087 & PknJ_0544 & DNTVGTDE & 177.3 & rpoB & RNA polymerase \\
\hline 799 & PknJ_0400 & VLVTGTVA & 177.7 & Rv2926c & \\
\hline 781 & PknJ_0391 & KPITGTHA & 178.2 & Rv2633c & \\
\hline 397 & PknJ_0199 & THVTATHY & 178.8 & $\operatorname{nadB}$ & L-Aspartate oxidase \\
\hline 267 & PknJ_0134 & GTVTLTFT & 179.6 & $i c d 1$ & Isocitrate dehydrogenase \\
\hline 279 & PknJ_0140 & SYLTQTTL & 180.2 & lytB1 & \\
\hline $649^{*}$ & PknJ_0325 & AWLTATPV & 180.3 & Rv1318c/Rv1320c & Adenylate cyclase \\
\hline 125 & PknJ_0063 & DSVTITGF & 180.5 & hupB & Histone-like \\
\hline 831 & PknJ_0416 & ITLTSTAD & 181.4 & Rv3740c & Triacylglycerol synthase \\
\hline 1107 & PknJ_0554 & GVTTQLGDDVA & 182.1 & $l p p I$ & Lipoprotein \\
\hline 399 & PknJ_0200 & EMVTLTID & 182.4 & nиоG & NADH dehydrogenase I \\
\hline 1067 & PknJ_0534 & VQETYTTL & 182.6 & Rv0635 & Fatty acid synthesis \\
\hline $1147^{\star \star}$ & PknJ_0574 & EKLTQLGNTVGT & 183.5 & pknE & STPK \\
\hline 129 & PknJ_0065 & VVLTATFA & 186.9 & $\operatorname{dip} Z$ & Cytochrome biogenesis \\
\hline 117 & PknJ_0059 & DLITGTDL & 187.9 & ctpI & P-type ATPase \\
\hline 1011 & PknJ_0506 & SIETPTPV & 188.4 & tatA & Sec-independent protein translocase \\
\hline 847 & PknJ_0424 & DGITGTLV & 188.6 & $m s h A$ & Glycosyltransferase \\
\hline 333 & PknJ_0167 & VPLTETAY & 189.4 & $m f d$ & Transcription-repair coupling factor \\
\hline $547^{\star * *}$ & PknJ_0274 & MLVTTTDA & 189.9 & $\operatorname{sod} C$ & Superoxide dismutase \\
\hline 761 & PknJ_0381 & VDITMTPA & 190.3 & Rv2560 & \\
\hline 487 & PknJ_0244 & FWVTGTSI & 191.2 & ppsA & PDIM synthesis \\
\hline 835 & PknJ_0418 & IGITVTDA & 191.6 & Rv3884c & \\
\hline 601 & PknJ_0301 & TLVTDTPG & 191.8 & Rv0010c & \\
\hline 141 & PknJ_0071 & LGVTVTVD & 192.9 & dnaJ2 & Chaperone \\
\hline $543^{\star * *}$ & PknJ_0272 & MLVTTTDA & 193.5 & $\operatorname{sod} C$ & Superoxide dismutase \\
\hline 459 & PknJ_0230 & $\underline{\text { TGLTSTGSII }}$ & 194.0 & $p k n J$ & STPK \\
\hline 745 & PknJ_0373 & GDVTETIR & 194.5 & pitB & Phosphate transport permease \\
\hline 401 & PknJ_0201 & GALTGTAY & 196.3 & nuoG & NADH dehydrogenase I \\
\hline 1085 & PknJ_0543 & NMTVGTVS & 197.5 & $p k n F$ & STPK \\
\hline 859 & PknJ_0430 & IHLTVTDV & 198.5 & Rv0887c & \\
\hline 481 & PknJ_0241 & MLVTQTSS & 199.0 & pra & Proline-rich antigen \\
\hline 405 & PknJ_0203 & AILTMTVG & 201.1 & nuoN & NADH dehydrogenase I \\
\hline 57 & PknJ_0029 & KLITYTSD & 202.3 & blaC & Beta-lactamase \\
\hline 225 & PknJ_0113 & LPVTWTVA & 202.4 & $i d s A 1$ & Lipid synthesis \\
\hline 1035 & PknJ_0518 & MPETPTGD & 203.9 & Rv1910c & \\
\hline 775 & PknJ_0388 & CRLTWTMA & 205.1 & Rv2574 & \\
\hline 65 & PknJ_0033 & TIITATFL & 205.6 & $c d s A$ & Phosphatidate cytidylyltransferase \\
\hline 569 & PknJ_0285 & SAVTGTDI & 207.7 & $\operatorname{trp} S$ & tRNA synthetase \\
\hline 173 & PknJ_0087 & LHVTWTGE & 208.5 & $e s x E$ & ESAT6-like protein \\
\hline 773 & PknJ_0387 & TKVTWTSP & 209.1 & Rv2574 & \\
\hline 755 & PknJ_0378 & VYLTVTGY & 209.6 & Rv2331 & \\
\hline 807 & PknJ_0404 & GVLTDTAS & 209.9 & Rv3400 & \\
\hline 261 & PknJ_0131 & DDVTETLE & 210.7 & hemC & Porphyrin synthesis \\
\hline 981 & PknJ_0491 & RAETSTPV & 212.9 & pyrD & Dihydroorotate dehydrogenase \\
\hline 567 & PknJ_0284 & SAVTGTDI & 213.7 & $\operatorname{trpS}$ & tRNA synthetase \\
\hline 353 & PknJ_0177 & VFVTSTVS & 214.0 & $m m p L 11$ & Fatty acid transport \\
\hline 409 & PknJ_0205 & PALTSTDY & 216.4 & aceE & Pyruvate dehydrogenase \\
\hline
\end{tabular}


Table 1. cont.

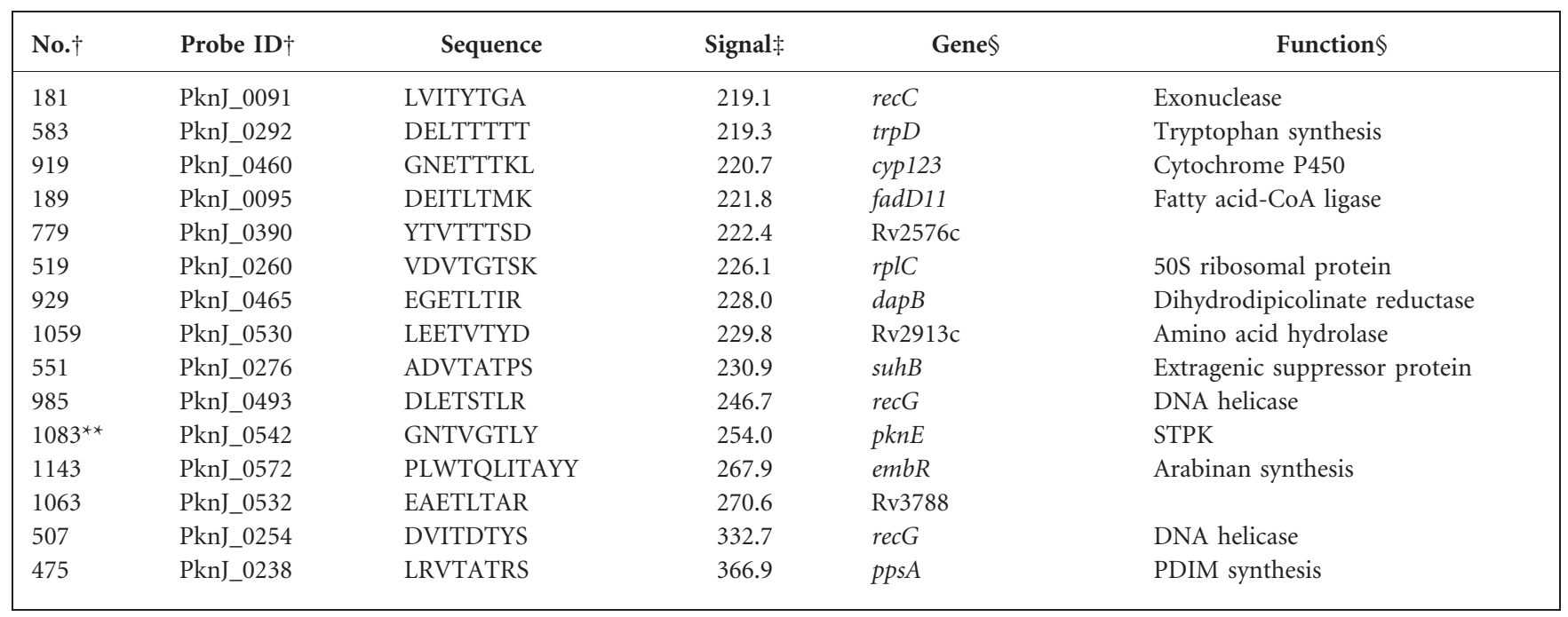

$\dagger$ No. and probe ID are given as in the raw data sheet (Table S3). Asterisks $\left(^{*}\right)$ indicate redundant probesets.

$\ddagger$ See Methods.

$\S$ Gene and function are given as in Tuberculist (http://genolist.pasteur.fr/TubercuList/). Function is putative or documented (see Tuberculist for details).

IIResidues identified by MS analysis as being phosphorylated are underlined.

\section{DISCUSSION}

We report the first topological and functional characterization of PknJ, the only M. tuberculosis STPK that has not previously been investigated. We recently suggested that the PknJ-encoding gene arose in the M. tuberculosis complex ancestor by horizontal gene transfer from environmental species (Becq et al., 2007). This may explain why PknJ is found only in species of the M. tuberculosis complex and not in other mycobacteria (Narayan et al., 2007). However, proteins annotated as 'PknJ' are found in other mycobacterial genomes available through various online databases. Close examination of the amino acid sequences of these homonyms showed similarity with $\mathrm{PknJ}$ either only in the $\mathrm{N}$-terminal kinase domain (e.g. in Mycobacterium marinum 'PknJ') or in the C-terminal extracellular domain (e.g. in Mycobacterium avium 'PknJ'). The M. avium 'PknJ', for example, lacks a detectable kinase domain (data not shown). This suggests either that (i) $M$. tuberculosis $\mathrm{PknJ}$ arose from gene fusion between an $M$. avium 'PknJ'-related protein and a functional kinase domain already present in an ancestral mycobacterial genome, or that (ii) M. avium 'PknJ' results from deletion of the kinase domain of an ancestral protein that has been transmitted to $M$. tuberculosis. Nevertheless, we propose that the name PknJ is kept only for Rv2088/PknJ found in M. tuberculosis and close relatives of the M. tuberculosis complex.

We show here that PknJ is a functional kinase that undergoes autophosphorylation when incubated with ATP, forms dimers in vitro and has a single transmembrane domain. These three features are shared by many other $M$. tuberculosis STPKs (Wehenkel et al., 2008). MS analysis and site-directed mutagenesis showed that the PknJ kinase domain autophosphorylates at threonine residues 168, 171 and 173 . We cannot rule out the possibility that there may also be multiple isoforms of the protein containing different numbers of phosphorylated threonine residues. Our peptide-chip analysis shows multiple potential targets for PknJ ( $\sim 0$ proteins). Phosphorylation of the peptides does not imply that all proteins containing these sequences are indeed phosphorylated, and we do not claim that these proteins are all PknJ substrates in vitro or in vivo, which should be evaluated on a case-by-case basis. STPKs can phosphorylate numerous substrates, and several STPKs can phosphorylate the same substrates (Grundner et al., 2005; Molle et al., 2006a). It is therefore likely that some of these proteins may be substrates for several $M$. tuberculosis STPKs, as well as for PknJ. We have confirmed four of these targets: (1) PknJ itself, (2) EmbR, which is also a substrate for PknH (Molle et al., 2003b) and other mycobacterial STPKs (Sharma et al., 2006a), (3) MmaA4/ Hma, a methyltranserase involved in the synthesis of mycolic acids, and (4) PepE, a putative dipeptidase with proline specificity (prolidase), whose gene maps next to $p k n J$ in the mycobacterial genome (Fig. 1a). This suggests that PknJ may be involved in nitrogen and amino acid metabolism, possibly through phosphorylation of PepE. Prolidase activation through phosphorylation has already been reported in other species (Surazynski et al., 2001), but it is not known whether this is also the case in M. tuberculosis. The finding that both the pknJ- and 
(a)

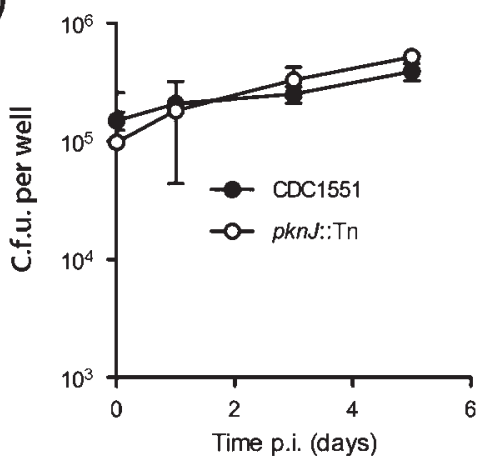

(b)

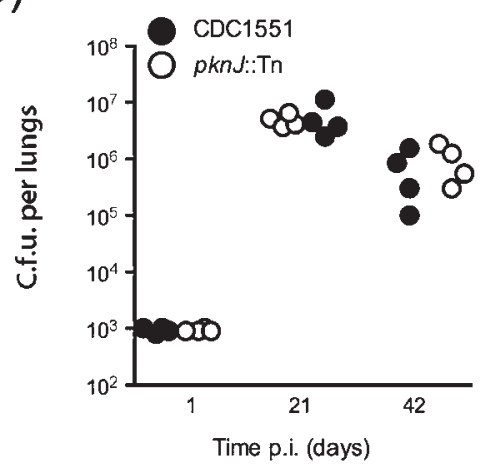

(c)

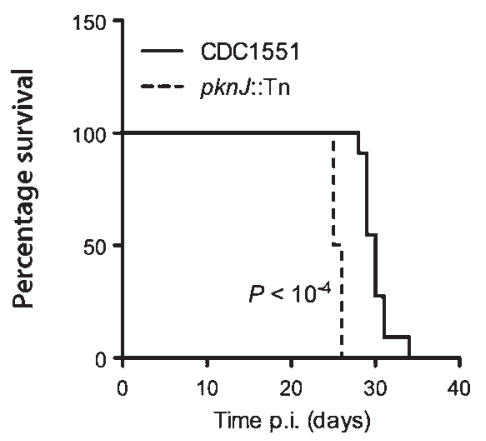

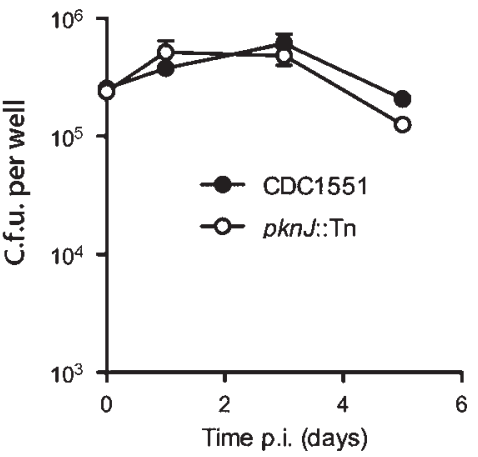

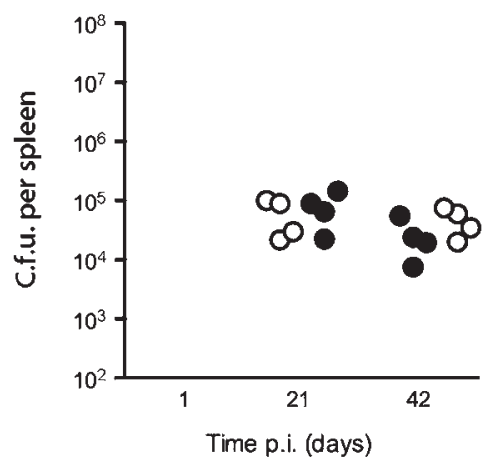

Fig. 5. PknJ does not contribute to mycobacterial virulence in the mouse model. (a) Inactivated (left) and activated (right) mouse bone-marrow-derived macrophages were infected with wild-type $M$. tuberculosis CDC1551 or with a CDC1551-derived pknJ transposon mutant. Cell lysates were plated and c.f.u. scored at various times. (b) Wildtype and mutant strains were used to infect BALB/c mice intranasally (1000 c.f.u. per mouse). After 1, 21 and 42 days of infection, lungs and spleen were homogenized and plated for c.f.u. scoring. (c) Wild-type and mutant strains were used to infect SCID mice intranasally (1000 c.f.u. per mouse), and animal survival was recorded. The figure shows one representative out of two independent experiments.
pepE-deficient mutants grow poorly in minimal medium unless BSA (a possible nitrogen source) is added supports this hypothesis.

The $p k n J$ mutant was found to be slightly hypervirulent in immunocompromised SCID mice. Although we could not restore the phenotype of the wild-type strain in the complemented mutant, this phenotype was strikingly similar to that of mycobacterial mutants defective in other STPKs, namely PknH (Papavinasasundaram et al., 2005) and PknI (Gopalaswamy et al., 2009). It may be explained by the low virulence of the CDC1551 mother strain as compared to other M. tuberculosis strains (Manca et al., 1999), and the role of PknJ in mycobacterial virulence may become more apparent in other experimental conditions (e.g. in other M. tuberculosis mother strains or in other animal models); it may also suggest that STPKs such as
PknH-J may play a part in mycobacterial virulence, which may be more apparent in other model systems. The exact function of PknJ (possibly in association with PepE) will thus require further investigation. More generally, our proteome-wide screening provides a list of putative substrates for M. tuberculosis PknJ, which may help better understanding of the function of this unique kinase in mycobacterial physiology.

\section{ACKNOWLEDGEMENTS}

We thank A. Wehenkell, M. Bellinzoni and P. M. Alzari for providing help at the start of the project. We thank Colorado State University for providing mycobacterial mutants (NIH, NIAID Contract No. HHSN266200400091C, 'Tuberculosis Vaccine Testing and Research Materials', awarded to CSU). B. M. was supported by grants from the Région Midi-Pyrénées, the FRM, and the ANR PFTV (Agence 
Nationale de la Recherche PlateFormes Technologiques du Vivant). This work was supported by the CNRS and the Institut Pasteur. J. J. was a fellow of the Fondation pour la Recherche Médicale (FRM). O.N. is a beneficiary of an ATIP grant from the CNRS.

\section{REFERENCES}

Av-Gay, Y. \& Everett, M. (2000). The eukaryotic-like Ser/Thr protein kinases of Mycobacterium tuberculosis. Trends Microbiol 8, 238-244.

Av-Gay, Y., Jamil, S. \& Drews, S. J. (1999). Expression and characterization of the Mycobacterium tuberculosis serine/threonine protein kinase PknB. Infect Immun 67, 5676-5682.

Becq, J., Gutierrez, M. C., Rosas-Magallanes, V., Rauzier, J., Gicquel, B., Neyrolles, O. \& Deschavanne, P. (2007). Contribution of horizontally acquired genomic islands to the evolution of the tubercle bacilli. Mol Biol Evol 24, 1861-1871.

Boissier, F., Bardou, F., Guillet, V., Uttenweiler-Joseph, S., Daffe, M., Quemard, A. \& Mourey, L. (2006). Further insight into $S$ adenosylmethionine-dependent methyltransferases: structural characterization of Hma, an enzyme essential for the biosynthesis of oxygenated mycolic acids in Mycobacterium tuberculosis. J Biol Chem 281, 4434-4445.

Camacho, L. R., Ensergueix, D., Perez, E., Gicquel, B. \& Guilhot, C. (1999). Identification of a virulence gene cluster of Mycobacterium tuberculosis by signature-tagged transposon mutagenesis. Mol Microbiol 34, 257-267.

Canova, M. J., Veyron-Churlet, R., Zanella-Cleon, I., CohenGonsaud, M., Cozzone, A. J., Becchi, M., Kremer, L. \& Molle, V. (2008). The Mycobacterium tuberculosis serine/threonine kinase PknL phosphorylates Rv2175c: mass spectrometric profiling of the activation loop phosphorylation sites and their role in the recruitment of Rv2175c. Proteomics 8, 521-533.

Chaba, R., Raje, M. \& Chakraborti, P. K. (2002). Evidence that a eukaryotic-type serine/threonine protein kinase from Mycobacterium tuberculosis regulates morphological changes associated with cell division. Eur J Biochem 269, 1078-1085.

Cohen-Gonsaud, M., Barthe, P., Canova, M. J., Stagier-Simon, C., Kremer, L., Roumestand, C. \& Molle, V. (2009). The Mycobacterium tuberculosis Ser/Thr kinase substrate Rv2175c is a DNA-binding protein regulated by phosphorylation. J Biol Chem 284, 1929019300.

Cole, S. T., Brosch, R., Parkhill, J., Garnier, T., Churcher, C., Harris, D., Gordon, S. V., Eiglmeier, K., Gas, S. \& other authors (1998). Deciphering the biology of Mycobacterium tuberculosis from the complete genome sequence. Nature 393, 537-544.

Cowley, S., Ko, M., Pick, N., Chow, R., Downing, K. J., Gordhan, B. G., Betts, J. C., Mizrahi, V., Smith, D. A. \& other authors (2004). The Mycobacterium tuberculosis protein serine/threonine kinase $\mathrm{PknG}$ is linked to cellular glutamate/glutamine levels and is important for growth in vivo. Mol Microbiol 52, 1691-1702.

Cox, J. S., Chen, B., McNeil, M. \& Jacobs, W. R., Jr (1999). Complex lipid determines tissue-specific replication of Mycobacterium tuberculosis in mice. Nature 402, 79-83.

Cozzone, A. J. (2005). Role of protein phosphorylation on serine/ threonine and tyrosine in the virulence of bacterial pathogens. $J \mathrm{Mol}$ Microbiol Biotechnol 9, 198-213.

Dasgupta, A., Datta, P., Kundu, M. \& Basu, J. (2006). The serine/ threonine kinase $\mathrm{PknB}$ of Mycobacterium tuberculosis phosphorylates PBPA, a penicillin-binding protein required for cell division. Microbiology 152, 493-504.
Deol, P., Vohra, R., Saini, A. K., Singh, A., Chandra, H., Chopra, P., Das, T. K., Tyagi, A. K. \& Singh, Y. (2005). Role of Mycobacterium tuberculosis Ser/Thr kinase PknF: implications in glucose transport and cell division. J Bacteriol 187, 3415-3420.

Deutscher, J. \& Saier, M. H., Jr (2005). Ser/Thr/Tyr protein phosphorylation in bacteria - for long time neglected, now well established. J Mol Microbiol Biotechnol 9, 125-131.

Drew, D., Sjostrand, D., Nilsson, J., Urbig, T., Chin, C. N., de Gier, J. W. \& von Heijne, G. (2002). Rapid topology mapping of Escherichia coli inner-membrane proteins by prediction and PhoA/GFP fusion analysis. Proc Natl Acad Sci U S A 99, 2690-2695.

Duran, R., Villarino, A., Bellinzoni, M., Wehenkel, A., Fernandez, P., Boitel, B., Cole, S. T., Alzari, P. M. \& Cervenansky, C. (2005). Conserved autophosphorylation pattern in activation loops and juxtamembrane regions of Mycobacterium tuberculosis Ser/Thr protein kinases. Biochem Biophys Res Commun 333, 858-867.

Feilmeier, B. J., Iseminger, G., Schroeder, D., Webber, H. \& Phillips, G. J. (2000). Green fluorescent protein functions as a reporter for protein localization in Escherichia coli. J Bacteriol 182, 4068-4076.

Fernandez, P., Saint-Joanis, B., Barilone, N., Jackson, M., Gicquel, B., Cole, S. T. \& Alzari, P. M. (2006). The Ser/Thr protein kinase $\mathrm{PknB}$ is essential for sustaining mycobacterial growth. $J$ Bacteriol 188, 7778-7784.

Gay, L. M., Ng, H. L. \& Alber, T. (2006). A conserved dimer and global conformational changes in the structure of apo-PknE Ser/Thr protein kinase from Mycobacterium tuberculosis. J Mol Biol 360, 409-420.

Good, M. C., Greenstein, A. E., Young, T. A., Ng, H. L. \& Alber, T. (2004). Sensor domain of the Mycobacterium tuberculosis receptor Ser/Thr protein kinase, $\mathrm{PknD}$, forms a highly symmetric beta propeller. J Mol Biol 339, 459-469.

Gopalaswamy, R., Narayanan, P. R. \& Narayanan, S. (2004). Cloning, overexpression, and characterization of a serine/threonine protein kinase pknI from Mycobacterium tuberculosis H37Rv. Protein Expr Purif 36, 82-89.

Gopalaswamy, R., Narayanan, S., Chen, B., Jacobs, W. R. \& Av-Gay, Y. (2009). The serine/threonine protein kinase PknI controls the growth of Mycobacterium tuberculosis upon infection. FEMS Microbiol Lett 295, 23-29.

Greenstein, A. E., MacGurn, J. A., Baer, C. E., Falick, A. M., Cox, J. S. \& Alber, T. (2007). M. tuberculosis Ser/Thr protein kinase D phosphorylates an anti-anti-sigma factor homolog. PLoS Pathog 3, e49.

Grundner, C., Gay, L. M. \& Alber, T. (2005). Mycobacterium tuberculosis serine/threonine kinases $\mathrm{PknB}, \mathrm{PknD}, \mathrm{PknE}$, and $\mathrm{PknF}$ phosphorylate multiple FHA domains. Protein Sci 14, 1918-1921.

Inouye, S. \& Nariya, H. (2008). Dual regulation with Ser/Thr kinase cascade and a His/Asp TCS in Myxococcus xanthus. In Bacterial Signal Transduction: Networks and Drug Targets, pp. 111-118. Edited by R. Utsumi. Springer Science.

Kang, C. M., Abbott, D. W., Park, S. T., Dascher, C. C., Cantley, L. C. \& Husson, R. N. (2005). The Mycobacterium tuberculosis serine/ threonine kinases PknA and PknB: substrate identification and regulation of cell shape. Genes Dev 19, 1692-1704.

Kang, C. M., Nyayapathy, S., Lee, J. Y., Suh, J. W. \& Husson, R. N. (2008). Wag31, a homologue of the cell division protein DivIVA, regulates growth, morphology and polar cell wall synthesis in mycobacteria. Microbiology 154, 725-735.

Koul, A., Choidas, A., Tyagi, A. K., Drlica, K., Singh, Y. \& Ullrich, A. (2001). Serine/threonine protein kinases $\mathrm{PknF}$ and $\mathrm{PknG}$ of Mycobacterium tuberculosis: characterization and localization. Microbiology 147, 2307-2314. 
Kumar, P., Kumar, D., Parikh, A., Rananaware, D., Gupta, M., Singh, Y. \& Nandicoori, V. K. (2009). The Mycobacterium tuberculosis protein kinase $\mathrm{K}$ modulates activation of transcription from the promoter of mycobacterial monooxygenase operon through phosphorylation of the transcriptional regulator VirS. J Biol Chem 284, 11090-11099.

Lakshminarayan, H., Narayanan, S., Bach, H., Sundaram, K. G. \& AvGay, Y. (2008). Molecular cloning and biochemical characterization of a serine threonine protein kinase, PknL, from Mycobacterium tuberculosis. Protein Expr Purif 58, 309-317.

Lamichhane, G., Zignol, M., Blades, N. J., Geiman, D. E., Dougherty, A., Grosset, J., Broman, K. W. \& Bishai, W. R. (2003). A postgenomic method for predicting essential genes at subsaturation levels of mutagenesis: application to Mycobacterium tuberculosis. Proc Natl Acad Sci U S A 100, 7213-7218.

LeBlanc, H. N. \& Beatty, J. T. (1996). Topological analysis of the Rhodobacter capsulatus PucC protein and effects of C-terminal deletions on light-harvesting complex II. J Bacteriol 178, 48014806.

Manca, C., Tsenova, L., Barry, C. E., III, Bergtold, A., Freeman, S., Haslett, P. A., Musser, J. M., Freedman, V. H. \& Kaplan, G. (1999). Mycobacterium tuberculosis CDC1551 induces a more vigorous host response in vivo and in vitro, but is not more virulent than other clinical isolates. J Immunol 162, 6740-6746.

Manoil, C. \& Beckwith, J. (1986). A genetic approach to analyzing membrane protein topology. Science 233, 1403-1408.

Martin, K., Steinberg, T. H., Cooley, L. A., Gee, K. R., Beechem, J. M. \& Patton, W. F. (2003). Quantitative analysis of protein phosphorylation status and protein kinase activity on microarrays using a novel fluorescent phosphorylation sensor dye. Proteomics 3, 12441255.

Mieczkowski, C., lavarone, A. T. \& Alber, T. (2008). Auto-activation mechanism of the Mycobacterium tuberculosis PknB receptor Ser/Thr kinase. EMBO J 27, 3186-3197.

Molle, V., Girard-Blanc, C., Kremer, L., Doublet, P., Cozzone, A. J. \& Prost, J. F. (2003a). Protein PknE, a novel transmembrane eukaryotic-like serine/threonine kinase from Mycobacterium tuberculosis. Biochem Biophys Res Commun 308, 820-825.

Molle, V., Kremer, L., Girard-Blanc, C., Besra, G. S., Cozzone, A. J. \& Prost, J. F. (2003b). An FHA phosphoprotein recognition domain mediates protein EmbR phosphorylation by $\mathrm{PknH}$, a Ser/Thr protein kinase from Mycobacterium tuberculosis. Biochemistry 42, 1530015309.

Molle, V., Soulat, D., Jault, J. M., Grangeasse, C., Cozzone, A. J. \& Prost, J. F. (2004). Two FHA domains on an ABC transporter, Rv1747, mediate its phosphorylation by $\mathrm{PknF}$, a Ser/Thr protein kinase from Mycobacterium tuberculosis. FEMS Microbiol Lett 234, 215-223.

Molle, V., Brown, A. K., Besra, G. S., Cozzone, A. J. \& Kremer, L. (2006a). The condensing activities of the Mycobacterium tuberculosis type II fatty acid synthase are differentially regulated by phosphorylation. J Biol Chem 281, 30094-30103.

Molle, V., Zanella-Cleon, I., Robin, J. P., Mallejac, S., Cozzone, A. J. \& Becchi, M. (2006b). Characterization of the phosphorylation sites of Mycobacterium tuberculosis serine/threonine protein kinases, PknA, PknD, PknE, and PknH by mass spectrometry. Proteomics 6, 37543766.

Munoz-Dorado, J., Inouye, S. \& Inouye, M. (1991). A gene encoding a protein serine/threonine kinase is required for normal development of M. xanthus, a gram-negative bacterium. Cell 67, 995-1006.

Narayan, A., Sachdeva, P., Sharma, K., Saini, A. K., Tyagi, A. K. \& Singh, Y. (2007). Serine threonine protein kinases of mycobacterial genus: phylogeny to function. Physiol Genomics 29, 66-75.
Nguyen, L., Walburger, A., Houben, E., Koul, A., Muller, S., Morbitzer, M., Klebl, B., Ferrari, G. \& Pieters, J. (2005). Role of protein kinase G in growth and glutamine metabolism of Mycobacterium bovis BCG. J Bacteriol 187, 5852-5856.

O'Hare, H. M., Duran, R., Cervenansky, C., Bellinzoni, M., Wehenkel, A. M., Pritsch, O., Obal, G., Baumgartner, J., Vialaret, J. \& other authors (2008). Regulation of glutamate metabolism by protein kinases in mycobacteria. Mol Microbiol 70, 1408-1423.

Ortiz-Lombardia, M., Pompeo, F., Boitel, B. \& Alzari, P. M. (2003). Crystal structure of the catalytic domain of the PknB serine/threonine kinase from Mycobacterium tuberculosis. J Biol Chem 278, 1309413100.

Papavinasasundaram, K. G., Chan, B., Chung, J. H., Colston, M. J., Davis, E. O. \& Av-Gay, Y. (2005). Deletion of the Mycobacterium tuberculosis $p k n H$ gene confers a higher bacillary load during the chronic phase of infection in BALB/c mice. J Bacteriol 187, 57515760.

Parikh, A., Verma, S. K., Khan, S., Prakash, B. \& Nandicoori, V. K. (2009). PknB-mediated phosphorylation of a novel substrate, $\mathrm{N}$ acetylglucosamine-1-phosphate uridyltransferase, modulates its acetyltransferase activity. J Mol Biol 386, 451-464.

Park, S. T., Kang, C. M. \& Husson, R. N. (2008). Regulation of the $\mathrm{SigH}$ stress response regulon by an essential protein kinase in Mycobacterium tuberculosis. Proc Natl Acad Sci U S A 105, 1310513110.

Perez, J., Garcia, R., Bach, H., de Waard, J. H., Jacobs, W. R., Jr, AvGay, Y., Bubis, J. \& Takiff, H. E. (2006). Mycobacterium tuberculosis transporter MmpL7 is a potential substrate for kinase PknD. Biochem Biophys Res Commun 348, 6-12.

Rousseau, C., Winter, N., Pivert, E., Bordat, Y., Neyrolles, O., Ave, P., Huerre, M., Gicquel, B. \& Jackson, M. (2004). Production of phthiocerol dimycocerosates protects Mycobacterium tuberculosis from the cidal activity of reactive nitrogen intermediates produced by macrophages and modulates the early immune response to infection. Cell Microbiol 6, 277-287.

Sharma, K., Gupta, M., Krupa, A., Srinivasan, N. \& Singh, Y. (2006a). EmbR, a regulatory protein with ATPase activity, is a substrate of multiple serine/threonine kinases and phosphatase in Mycobacterium tuberculosis. FEBS J 273, 2711-2721.

Sharma, K., Gupta, M., Pathak, M., Gupta, N., Koul, A., Sarangi, S., Baweja, R. \& Singh, Y. (2006b). Transcriptional control of the mycobacterial embCAB operon by $\mathrm{PknH}$ through a regulatory protein, EmbR, in vivo. J Bacteriol 188, 2936-2944.

Stadthagen, G., Sambou, T., Guerin, M., Barilone, N., Boudou, F., Korduláková, J., Charles, P., Alzari, P. M., Lemassu, A. \& other authors (2007). Genetic basis for the biosynthesis of methylglucose lipopolysaccharides in Mycobacterium tuberculosis. J Biol Chem 282, 27270-27276.

Sun, H., Lu, C. H., Shi, H., Gao, L. \& Yao, S. Q. (2008). Peptide microarrays for high-throughput studies of Ser/Thr phosphatases. Nat Protoc 3, 1485-1493.

Surazynski, A., Palka, J. \& Wolczynski, S. (2001). Phosphorylation of prolidase increases the enzyme activity. Mol Cell Biochem 220, 95-101.

Szekely, R., Waczek, F., Szabadkai, I., Németh, G., HegymegiBarakonyi, B., Eros, D., Szokol, B., Pató, J., Hafenbradl, D. \& other authors (2008). A novel drug discovery concept for tuberculosis: inhibition of bacterial and host cell signalling. Immunol Lett 116, 225231.

Thakur, M. \& Chakraborti, P. K. (2006). GTPase activity of mycobacterial FtsZ is impaired due to its transphosphorylation by the eukaryotic-type Ser/Thr kinase, PknA. J Biol Chem 281, 4010740113 . 
Thakur, M. \& Chakraborti, P. K. (2008). Ability of PknA, a mycobacterial eukaryotic-type serine/threonine kinase, to transphosphorylate MurD, a ligase involved in the process of peptidoglycan biosynthesis. Biochem J 415, 27-33.

Veyron-Churlet, R., Molle, V., Taylor, R. C., Brown, A. K., Besra, G. S., Zanella-Cleon, I., Futterer, K. \& Kremer, L. (2009). The Mycobacterium tuberculosis beta-ketoacyl-acyl carrier protein synthase III activity is inhibited by phosphorylation on a single threonine residue. J Biol Chem 284, 6414-6424.

Villarino, A., Duran, R., Wehenkel, A., Fernandez, P., England, P., Brodin, P., Cole, S. T., Zimny-Arndt, U., Jungblut, P. R. \& other authors (2005). Proteomic identification of $M$. tuberculosis protein kinase substrates: PknB recruits GarA, a FHA domain-containing protein, through activation loop-mediated interactions. J Mol Biol 350, 953-963.

Walburger, A., Koul, A., Ferrari, G., Nguyen, L., PrescianottoBaschong, C., Huygen, K., Klebl, B., Thompson, C., Bacher, G. \&
Pieters, J. (2004). Protein kinase G from pathogenic mycobacteria promotes survival within macrophages. Science 304, 1800-1804.

Wehenkel, A., Bellinzoni, M., Grana, M., Duran, R., Villarino, A., Fernandez, P., Andre-Leroux, G., England, P., Takiff, H. \& other authors (2008). Mycobacterial Ser/Thr protein kinases and phosphatases: physiological roles and therapeutic potential. Biochim Biophys Acta 1784, 193-202.

Young, T. A., Delagoutte, B., Endrizzi, J. A., Falick, A. M. \& Alber, T. (2003). Structure of Mycobacterium tuberculosis $\mathrm{PknB}$ supports a universal activation mechanism for Ser/Thr protein kinases. Nat Struct Biol 10, 168-174.

Zhang, C. C., Gonzalez, L. \& Phalip, V. (1998). Survey, analysis and genetic organization of genes encoding eukaryotic-like signaling proteins on a cyanobacterial genome. Nucleic Acids Res 26, 36193625 .

Edited by: S. V. Gordon 